\title{
Early psychological intervention following the 2014 Nepal snowstorm
}

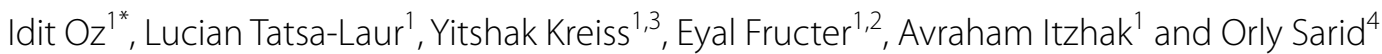

\begin{abstract}
The following is a case study of the blizzard of October 2014, an Israeli rescue team, the Special Mental Health Team (SMHT) of the Israeli Defense Forces Medical Corps, was sent to the disaster area to rescue Israeli trekkers. The SMHT intervention was provided immediately following the traumatic events with the purpose of lowering stress-related symptoms, shortening recovery time and reducing post-traumatic stress disorder symptoms that could occur in the future. Forty Israeli trekkers were assessed by SMHT: $75 \%(n=30)$ had mild acute stress reaction (ASR) symptoms and $25 \%(n=10)$ had severe acute stress disorder (ASD) symptoms. All participating trekkers receiving the intervention as a way to alleviate symptoms reported no symptoms of ASR and ASD following the intervention. Trekkers with mild ASR reported full recovery after 1 week and trekkers with ASD reported full recovery after 3 months. This case study describes the psychological intervention conducted by SMHT for the surviving trekkers following the blizzard and aims to extend the knowledge base of mental health intervention at the early phases of disaster. A research study should be conducted to develop a measurement tool capable of evaluating the effect of a short-term intervention conducted in the field.
\end{abstract}

Keywords: Mental health intervention, Early phase of disaster, Acute stress reaction, Acute stress disorder

\section{Background}

The State of Israel considers it to be highly important to provide humanitarian assistance during disasters as well as assistance to the population during times of distress anywhere in the world. Due to these principles, the Israeli government sent a humanitarian aid delegation to Nepal following the blizzard of October 2014. As part of an Israeli effort to extend immediate medical and mental care to the survivors, rescue teams were sent to Nepal, including medical professionals and a Special Mental Health Team (SMHT) of the Israeli Defense Forces Medical Corps (IDF-MC). The SMHT has gained considerable experience in frontline early intervention missions that were conducted in war zones and in humanitarian military missions sent to natural disaster areas. These interventions were aimed at lowering the severity of symptoms occurring immediately after traumatic events as a way to shorten the recovery time [1-3] and reduce

*Correspondence: iditoz@inter.net.il

1 Israel Defense Forces, Medical Corps, Ramat Gan, Israel

Full list of author information is available at the end of the article later symptoms of post-traumatic stress disorder (PTSD) [4].

The snowstorm and a series of avalanches occurred around Annapurna and Dhaulagiri, in the Manang and Mustang Districts of Nepal, within the Himalaya ridge [5]. The storm, aroused from Cyclone "Hudhud", caused deaths of 43 people and wounded 175 persons [6-10]. Among the dead were 21 trekkers from Canada, India, Israel, Nepal, Poland, and Slovakia walking the "Annapurna Circuit" [10], as well as several local Nepali mountain guides and yak herders [11]. Injured survivors were given immediate medical attention following the disaster, and many of them suffered from ASR.

\section{Literature review \\ Reactions to disasters}

The field of mental health in disasters consists of several phases of prevention and intervention [12-15]. In the first phase, pre-disaster preparation, officials and providers planned ahead psycho-education models which included: risks and consequences to individuals, families and communities, education and mobilization of 
potential responders [12-15]. The second phase starts when disaster strikes, disaster impact phase $[13,14,16]$. Relying on Maslow's hierarchy of needs, physical safety and security are of the utmost importance at this time. Mental reaction is often seen as a state of psychological shock, ranging from numbness and immobilization to frantic attempts to flee or heroic efforts to respond and help others [12-15]. The intervention at this stage includes psychological first aid (PFA) [12, 13, 15] such as providing information and connecting people with loved ones and resources [17].

The third phase is the short-term adaptation phase, which could last from $24 \mathrm{~h}$ to 3 months [12]. The loss, destruction, and grief are inescapable realities confronting individuals, families and communities. Services, community networks, and social supports are still disrupted, as are routines. During this period, mental health interventions include psychosocial identifying, validating, and normalizing reactions, and intervening with small groups and families [14].

The final phase, recovery phase [13], or long-term adaptation phase [12-14] is characterized by a gradual return to routine activities. Most acute phase reaction subsides by this time, yet a minority of people will develop chronic severe reactions [14].

\section{Intervening in disaster times}

The guiding principles for early intervention are suggested in the literature aiming to promote a sense of safety and calmness, enhance self and collective efficacy, increase connectedness and hope [18]. Psychosocial recovery involves achieving these principles at the individual, group, and community levels in a manner consistent with local and cultural norms and practices [18]. Hobfoll has noted that recovery depends on individuals' and communities' resilience thus universal models of recovery need to be contextualized [18].

When conducting a post-disaster intervention, researchers acknowledge the importance of identifying vulnerable individuals [19]. For example, Rosenfeld [14] describes circles of vulnerability that radiate out from the disaster zone. The basic tenet is that the most vulnerable people, physically and psychosocially, are those closest to the epicenter of the disaster.

The PFA approach was developed by the National Center for Post-Traumatic Stress Disorder (NC-PTSD) a section of the United States Department of Veterans Affairs, in 2006, in order to address the psychosocial needs of individuals in major traumatic events. Key components of this approach involves the provision of an opportunity to talk while respecting the desire not to talk about the traumatic experience; assessing basic and physical needs and ensuring that these are met; promoting positive coping mechanisms; supportive advice and linking people with sources of support; encouraging the participation in normal daily routines. Providers are called to identify those who need further help and facilitate referral to more specialist services when indicated [20].

Another model which focuses on vulnerable individuals is the critical incident stress management (CISM) model [21-24]. This model aims to normalize reactions, provide health education on possible future reactions and conduct debriefing, which is reviewing the traumatic experience, encouraging emotional expression and promoting cognitive processing [25]. For the past several years, the topic of CISM has generated a controversy in the field of disaster mental health. Practitioners and trained peer responders still use debriefings after disasters, though in an adapted form [26-31].

Previous studies on disaster intervention have focused on intervention provided to the rescue and medical teams [32-37]. Yet, very few studies have followed survivors at the short-term adaptation phase that have received a mental health intervention [38]. This case study aims to describe the psychological intervention conducted by the Israeli SMHT for the Israeli trekkers following the snowstorm disaster. Its second aim is to extend the knowledge base of mental health intervention at the early phase of disaster.

\section{Case presentation \\ Process}

The Israeli team that was sent to Nepal included search and rescue forces, volunteers, medical services and the SMHT. All worked jointly with the local Nepalese rescue team.

The SMHT arrived at Nepal 4 days following the disaster, amidst the short-term adaptation phase. The team included a psychiatrist, a social worker and a trauma surgeon who was in charge of managing the team and the provision of combined mental and physical injuries. The team stayed in Nepal for 1 week, provided assistance to whoever asked for it. However, most help seekers were Israeli trekkers.

The Israeli survivors were spread throughout the city of Katmandu. The process of locating them took about 2 days. The reaching out was made possible by teaming up with the local disaster management including officials, volunteers and rescue teams who helped to spread the word through all media and network options. Furthermore, a well-known Jewish center-"The Chabad House" in Katmandu was transformed by local officials to a support center for all of the Israeli survivors. It served as a place for therapeutic interventions. 


\section{The trekker population}

120 Israeli trekkers were trapped in the blizzard, more than 50 of them were located in the "Tharong La" mountain pass and were exposed to the most extreme blizzard conditions. Four Israelis lost their lives and seven were wounded. Out of the remaining trekkers who were in "Tharong La", thirty trekkers independently contacted SHMT for psychological assistance and 10 trekkers were sent by local aid organizations. All in all, 40 Israeli trekkers were treated by the SMHT. All trekkers reported experiencing extreme natural conditions. They suffered from hypothermia, frost-bites, altitude sickness and snow blindness. Thirty trekkers exhibited mild ASR symptoms and 10 trekkers exhibited severe ASD symptoms.

The trekkers' ages were between 20 and 37. The great majority were after completing their military service and few of them were college students on vacation.

\section{The intervention}

The intervention responded to the needs of individuals in the third phase. It included PFA and CISM. The protocol was conducted as follows:

1. Reaching out-The SMHT members reached out to survivors by "actively hanging out" in the area and providing practical help as well as counseling.

2. Therapeutic alliance-were formed by the SMHT with the trekkers.

3. As recommended in the literature [39], SMHT did not replace local helping networks but rather supported and strengthened them. In practice, this meant an assessment and engagement of resourceful community personnel such as the Israeli Embassy, the 'Chabad House' personnel, and specific individuals involved in the disaster and rescuing efforts.

4. The SMHT identified and mapped circles of vulnerability looking for the survivors who fell into the first circle of vulnerability-the ones who had directly experienced the disaster.

5. Following the PFA [40]—vulnerable individuals were provided with physical and mental aid. Their coping skills and mental resilience were evaluated. Reactions to disaster were normalized and psycho-educational explanation about typical reactions was combined with an emphasis on self-care. Individuals were linked to sources of support, and encouraged to keep normal daily routines. The team identified those who need further help and referred them to special services when necessary.

6. Individual and group sessions were provided-following the primary assessment of trekkers by SMHT members, two groups of interventions were formed. The first group consisted of 30 participants, with mild ASR symptoms. Symptoms were assessed by the SMHT team for each individual upon joining the group and 1 week later. The group met for one session that lasted about $2 \mathrm{~h}$. Elements of modified debriefing were introduced as a way of constructing a mutual narrative of the disaster.

The second group had 10 participants with severe symptoms of ASD, symptoms were assessed at three time points: T1: upon joining the group, T2: 2 days later during which they received a group intervention that lasted for $2 \mathrm{~h}$ and incorporated elements of modified debriefing. Participants underwent 1-3 individual sessions which focused on cognitive behavioral interventions. T3: 3 months later by phone. At T3 each individual was also assessed by answering the PTSD Checklist for DSM- 5 (PCL-5) questionnaire. Group sessions were led by two SMHT members.

\section{Symptoms}

Symptoms of ASR were assessed during an interview according to ICD-10 [41] and ASD symptoms were assessed according to the Fifth Edition of the Diagnostic and Statistical Manual of Mental Disorders [42]. Symptoms included lack of sleep, intrusive thoughts, emotional flooding, increased arousal, flashbacks, guilt and shame, levels of dissociation and emotional detachment, anxiety attacks, tantrums, and psychomotor restlessness.

PTSD symptoms in the trekkers were evaluated with the PCL-5 Questionnaire-PCL-5 Questionnaire, a 20-item self-report measure that assesses the 20 DSM-5 symptoms of PTSD [43]. Scores above 50 are defined as PTSD.

\section{Symptoms assessment}

Seventy-five percent of the trekkers $(\mathrm{n}=30)$ were assessed as having mild ASR. At the first measurement point, they reported symptoms such as crying, sadness, fear, headaches, physiological pain without injury, feelings of detachment, difficulty in concentrating and anger. At the second point, 1 week later, all trekkers reported positive improvement in their symptoms. For example, all could sleep throughout the night [44]. Trekkers commented that the group intervention assisted in normalizing their stress response and provided knowledge regarding self-care processes. They stated that building a group narrative about the disaster made them feel more resourceful and gave them a greater sense of coherence.

Twenty-five percent of the trekkers $(n=10)$ were assessed with severe ASD symptoms. At T1 they reported lack of sleep for more than three consecutive days, intrusive thoughts, emotional flooding, increased arousal, flashbacks of people who died in the snow, guilt and shame 
regarding not being able to help friends who did not survive the journey, and varying levels of dissociation and emotional detachment. They suffered from anxiety attacks, tantrums, and psychomotor restlessness. At T2 they reported a reduction in the level of their symptoms. All managed to sleep throughout the night. At T3, 3 months later, the mean score of PCL-5 scale was $19.4 \pm 11.89$ (median $=19.5)$. At T3, all ten trekkers reported no symptoms of PTSD and that they had returned to a full and healthy level of functioning in all areas of their lives. The trekkers highly valued the group intervention where they could share their cognitive, emotional and physical reactions and reflect on themselves and on other people's range of reactions. They stated that the group discussions became part of the process of mourning and remembering. Together with the self-care strategies taught by the SMHT members, compassion and empathy to oneself and others, the trekkers managed to cope.

\section{Conclusions}

This case study described a group intervention and elements of modified debriefing as adapted from CISM [21-23] among forty vulnerable individuals in the second phase of disaster.

All participating trekkers receiving the intervention as a way to alleviate symptoms reported no ASR and ASD symptoms following the intervention. Several explanations are offered for this outcome. The first explanation draws from the common background of the trekkers and the SMHT members. Team members and trekkers were Hebrew-speakers who served in the IDF. A common background may have contributed to the strong therapeutic alliance between the team and the trekkers. We believe that this alliance enhanced trust and support which in turn enhanced resilience. Second, during the days when the intervention took place, the SMHT maintained continuity with avalanche survivors, normalized their reactions, created cognitive restructuring and provided an ongoing sense of care, which all in all helped in lowering the level of symptoms.

It is also suggested that the group setting conducted by the SMHT helped participants in constructing a continuous narrative about what happened to them during and after the stressful situation [46]. Reduction of ASR symptoms among our participants' corroborated results from another study showing that intervening at an early stage when memory consolidation of the traumatic event is not fully consolidated, prevents the formation of future traumatic, intrusive memories. We suggest that group intervention enhanced cohesion, decreased mental and physical isolation, and assisted in the creation of a group narrative of the event and its aftermath. This reduced ASR symptoms and enabled a better recovery [30, 45].
Ten trekkers with severe ASD symptoms, who received group and individual intervention in the early phase, fully recovered, as was measured by the PCL-5 Questionnaire 3 months later, and none developed PTSD. Another possible explanation for the decrease of symptoms is that interventions provided social support [4], which increased hope among the survivors. Hope made it possible to recruit positive mental resources and thus shaped the manner in which the traumatic events were consolidated and recalled [46, 47].

This case study shows that it would be beneficial to conduct future studies on short-term intervention after disaster and to create a measurement tool, such as a selfreport questionnaire, for the evaluation of the effects of short-term intervention conducted in the field.

\section{Abbreviations \\ SMHT: Special Mental Health Team; IDF-MC: Israeli Defense Forces Medical Corps; PTSD: post-traumatic stress disorder; ASR: acute stress reaction; ASD: acute stress disorder; PFA: psychological first aid; NC-PTSD: National Center for Post-Traumatic Stress Disorder; CISM: critical incident stress management; PCL-5: PTSD Checklist for DSM-5.}

\section{Authors' contributions}

IO participated in data collection, intervention, analysis, and wrote the manuscript. LTL participated in data collection, intervention, and helped write the manuscript. Al participated in data collection and intervention. YK initiated SMHT and helped draft the manuscript. EF helped in researching for the manuscript. OS participated in analysis, provided theoretical aspects and helped write the manuscript. All authors read and approved the final manuscript.

\section{Author details \\ ${ }^{1}$ Israel Defense Forces, Medical Corps, Ramat Gan, Israel. ${ }^{2}$ CIR, UCS-School of Social Work, Los Angeles, California, USA. ${ }^{3}$ Department of Military Medicine, Hebrew University, Jerusalem, Israel. ${ }^{4}$ Department of Social Work, Ben Gurion University of the Negev, Be'er Sheva, Israel.}

\section{Competing interests}

The authors declare that they have no competing interests.

\section{Ethics approval}

The institutional review board of IDF Medical Corps approved the study and waived the requirement for informed consent in order to protect participant anonymity.

Received: 31 March 2016 Accepted: 10 May 2016

Published online: 23 May 2016

\section{References}

1. Rose S, Bisson J, Churchill R, Wessely S. Psychological debriefing for preventing post traumatic stress disorder (PTSD). Cochrane Database Syst Rev 2002; 2(2):2-6.

2. Reyes G, Elhai JD. Psychosocial interventions in the early phases of disasters. Psychotherapy. 2004;41(4):399-411.

3. Roberts NP, Kitchiner NJ, Kenardy J, Bisson Jl. Systematic review and meta-analysis of multiple-session early interventions following traumatic events. Am J Psychiatry. 2009;166(3):293-301.

4. Litz BT, Gray MJ, Bryant RA, Adler AB. Early intervention for trauma: Current status and future directions. Clin Psychol Sci Pract. 2002;9(2):112-34.

5. Nepal annapurna: Search ends for surviving trekkers. http://www.bbc. com/news/world-asia-29679773. Accessed August 2015. 
6. Himalayan blizzard, avalanche kill 17 trekkers in nepal. https://www yahoo.com/news/four-killed-himalayan-snowstorm-080319156. html?ref=gs. Accessed August 2015 .

7. Death toll in nepal's worst trekking disaster reaches 43. http://www. reuters.com/article/us-nepal-hikers-idUSKCNOIA1XU20141021. Accessed August 2015.

8. Blizzard and avalanche kill at least 20 trekkers in himalayas. http://www. nytimes.com/2014/10/16/world/asia/himalayas-blizzard-and-avalanchekill-at-least-20-and-leave-dozens-missing.html?_r=0. Accessed August 2015.

9. Freak nepal blizzards kill at least 20, including hikers, guides. http://www. reuters.com/article/us-nepal-hikers-snowfall-idUSKCNO|40U620141015. Accessed August 2015.

10. Nepal tightens up mountain rules in wake of himalayan hiking disaster. http://www.theguardian.com/world/2014/oct/21/nepal-mountain-ruleshimalyan-hiking-disaster. Accessed August 2015.

11. Nepal trekking disaster: Britons still 'missing' after severe snow storm. http://www.telegraph.co.uk/news/worldnews/asia/nepal/11171247/ Nepal-trekking-disaster-Britons-still-missing-after-severe-snow-storm. html. Accessed August 2015.

12. Vernberg EM, Vogel JM. Part ii: Interventions with children after disasters, J Clin Child Psychol 1993; 22(4):485-498.

13. Alexander DA. Early mental health intervention after disasters. Adv Psychiatr Treat. 2005;11(1):12-8.

14. Rosenfeld LB, Caye JS, Ayalon O, Lahad M. When their world falls apart: helping families and children manage the effects of disasters. Soc Work. 2007:52(2):187.

15. Halpern J, Tramontin M. Disaster mental health: Theory and practice. Belmont, CA : Thomson Brooks/Cole; 2007. p. 17-45, 199-223.

16. Raphael B. Overview of the development of psychological support in emergencies. In: Diaz JOP, Murthy RS, Lakshminarayana R, editors. Overview of the development of psychological support in emergencies. Advances in disaster mental health and psychological support. New Delhi, India: Voluntary Health Association of India Press; 2006.

17. Orner RJ, Kent AT, Pfefferbaum BJ, Raphael B, Watson PJ. The context of providing immediate postevent intervention. In: Ritchie EC, Watson PJ, Friedman MJ, editors. The context of providing immediate postevent intervention. Interventions following mass violence and disasters: strategies for mental health practice. New York: Guilford; 2006.

18. Hobfoll SE, Watson P, Bell CC, Bryant RA, Brymer MJ, Friedman MJ, Friedman $M$, Gersons BP, de Jong JT, Layne CM, et al. Five essential elements of immediate and mid-term mass trauma intervention: empirical evidence. Psychiatry. 2007;70(4):283-316.

19. Kaniasty K, Norris F. The experience of disaster: Individuals and communities sharing trauma. In: Gist R, Lubin B, editors. The experience of disaster: Individuals and communities sharing trauma. Response to disaster: psychosocial, community and ecological approaches. Philadelphia: Brunner/ Mazel; 1999.

20. Everly GS Jr, Phillips SB, Kane D, Feldman D. Introduction to and overview of group psychological first aid. Brief Treat Crisis Interv. 2006;6(2):130-6.

21. Mitchell JT. When disaster strikes: the critical incident stress debriefing process. J Emerg Med Serv. 1983;8(1):36-9.

22. Mitchell JT, Bray GP. Emergency services stress: guidelines for preserving the health and careers of emergency services personnel. Ellicot City: Chevron Publishing; 1990.

23. Mitchell JT, Everly GS. The basic critical incident stress management course. Ellicott City: International Critical Incident Stress Foundation; 2001.

24. Miller JL. Critical incident stress debriefing and social work: expanding the frame. J Soc Serv Res. 2003;30(2):7-25.

25. Kaplan Z, lancu I, Bodner E. A review of psychological debriefing after extreme stress. Psychiatr Serv. 2001;52(6):824-7.

26. Chemtob CM, Tomas S, Law W, Cremniter D. Postdisaster psychosocial intervention: a field study of the impact of debriefing on psychological stress. Am J Psychiatry. 1997;154(3):415-7.

27. Bisson Jl, McFarlane AC, Rose S. Psychological debriefing. In: Foa EB, Keane TM, Friedman MJ, editors. Psychological debriefing. Effective treatments for PTSD: practice guidelines from the international society for traumatic stress studies. New York: Guilford; 2000.

28. Deahl M. Psychological debriefing: controversy and challenge. Aust N Z J Psychiatry. 2000;34(6):929-39.
29. Everly GS, Mitchell JT. The debriefing "controversy" and crisis intervention: a review of lexical and substantive issues. Int J Emerg Ment Health. 2000:2(4):211-25.

30. Dyregrov A. Psychological debriefing: a leader's guide for small group crisis intervention. Ellicott City: Chevron Publishing; 2003.

31. Bisson Jl, Andrew M. Psychological treatment of post-traumatic stress disorder (PTSD) (Review). New York: Wiley; 2007.

32. Armstrong K, O'Callahan W, Marmar CR. Debriefing red cross disaster personnel: the multiple stressor debriefing model. J Trauma Stress. 1991;4(4):581-93.

33. Figley CR. Compassion fatigue as secondary traumatic stress disorder: an overview. In: Figley CR, editor. Compassion fatigue as secondary traumatic stress disorder: an overview. Compassion fatigue: coping with secondary traumatic stress disorder in those who treat the traumatized. New York: Brunner/Mazel; 1995.

34. Alvarez J, Hunt M. Risk and resilience in canine search and rescue handlers after 9/11. J Trauma Stress. 2005;18(5):497-505.

35. Adams RE, Boscarino JA, Figley CR. Compassion fatigue and psychological distress among social workers: a validation study. Am J Orthopsychiatry. 2006;76(1):103-8.

36. Adams LM. Mental health needs of disaster volunteers: a plea for awareness. Perspect Psychiatr Care. 2007:43(1):52-4.

37. Alden LE, Regambal MJ, Laposa JM. The effects of direct versus witnessed threat on emergency department healthcare workers: implications for ptsd criterion a. J Anxiety Disord. 2008;22(8):1337-46.

38. Math SB, Girimaji SC, Benegal V, Uday Kumar GS, Hamza A, Nagaraja D. Tsunami: psychosocial aspects of andaman and nicobar islands. Assessments and intervention in the early phase. Int Rev Psychiatry. 2006:18(3):233-9.

39. Miller JL. Psychosocial capacity building in response to disasters. New York: Columbia University Press; 2012.

40. Brymer M, Layne C, Jacobs A, Pynoos R, Ruzek J, Steinberg A, Vernberg E, Watson P. Psychological first aid field operations guide. National Child Traumatic Stress Network; 2006. p. 109-118.

41. World Health Organisation. Icd-10 classifications of mental and behavioural disorder: clinical descriptions and diagnostic guidelines. Geneva: World Health Organisation; 1992.

42. American Psychiatric Association. Diagnostic and statistical manual of mental disorders. 5th ed. Washington, DC: APA; 2013.

43. Weathers FW, Litz BT, Keane TM, Palmieri PA, Marx BP, Schnurr PP. The ptsd checklist for dsm-5 (pcl-5). In. The ptsd checklist for dsm-5 (pcl-5). The National Center for PTSD. 2013. www.ptsd.va.gov.

44. Germain A. Sleep disturbances as the hallmark of ptsd: where are we now? Am J Psychiatry. 2013:170(4):372-82.

45. Dyregrov A. The process in psychological debriefings. J Trauma Stress. 1997:10(4):589-605.

46. Levi O, Liechtentritt R, Savaya R. Posttraumatic stress disorder patients' experiences of hope. Qual Health Res. 2012;22(12):1672-84.

47. Levi O. Individual therapy via the phenomenon of hope for treating chronic and complex ptsd. Psychoanal Soc Work. 2013;20(2):150-73.

\section{Submit your next manuscript to BioMed Central and we will help you at every step:}

- We accept pre-submission inquiries

- Our selector tool helps you to find the most relevant journal

- We provide round the clock customer support

- Convenient online submission

- Thorough peer review

- Inclusion in PubMed and all major indexing services

- Maximum visibility for your research

Submit your manuscript at www.biomedcentral.com/submit 